\title{
FGF23-klotho axis as predictive factors of fractures in type 2 diabetics with early chronic kidney disease
}

\author{
Ana Luísa Ribeiro ${ }^{\mathrm{b}, *}$, Filipa Mendes a ${ }^{\mathrm{a}}$ Eduarda Carias ${ }^{\mathrm{a}}$, Fátima Rato ${ }^{\mathrm{c}}$, Nélio Santos ${ }^{\mathrm{c}}$, \\ Pedro Leão Neves ${ }^{\mathrm{a}, \mathrm{b}}$, Ana Paula Silva ${ }^{\mathrm{a}, \mathrm{b}}$ \\ a Department of Nephrology, Centro Hospitalar Universitário do Algarve, Faro, Portugal \\ b Department of Biomedical Sciences and Medicine, University of Algarve, Faro, Portugal \\ c Pathology Clinic, Centro Hospitalar Universitário do Algarve, Faro, Portugal
}

\section{A R T I C L E I N F O}

\section{Article history:}

Received 24 August 2019

Received in revised form 12 October 2019

Accepted 28 October 2019

Available online 31 October 2019

\section{Keywords:}

Bone fracture

Chronic kidney disease

Diabetes

FGF-23

\begin{abstract}
A B S T R A C T
Background: The aim of our study was to evaluate the relevance of FGF23-klotho axis in the predisposition for bone fractures in type 2 diabetic patients with early chronic kidney disease.

Methods: In a prospective study we included 126 type 2 diabetic patients with CKD stages 2-3 (from 2010 to 2017). We used descriptive statistics, ANOVA and chi-square test. Our population was divided into two groups according to the occurrence of a bone fracture event or not, and the groups were compared considering several biological and laboratorial parameters. We employed a multiple regression model to identify risk factors for bone fracture events and hazard ratios (HR) were calculated using a backward stepwise likelihood ratio (LR) Cox regression.

Results: Patients with a fracture event displayed higher levels of FGF-23, Phosphorus, PTH, TNF- $\alpha$, OxLDL, HOMA-IR, calcium $\times$ phosphorus product and ACR and lower levels of Osteocalcin, $\alpha$-Klotho, 25(OH)D3 and eGFR compared with patients without a fracture event $(p<0.001)$. The number of patients with a fracture event was higher than expected within inclining CKD stages $(\chi 2, p=0.06)$. The occurrence of fracture and the levels of TNF- $\alpha$, klotho, $25(\mathrm{OH}) \mathrm{D} 3$ and OxLDL were found to predict patient entry into RRT $(p<0.05)$. Age, osteocalcin, $\alpha$-Klotho and FGF-23 independently influenced the occurrence of bone fracture $(p<0.05)$.

Conclusions: $\alpha$-Klotho and FGF-23 levels may have a good clinical use as biomarkers to predict the occurrence of fracture events.
\end{abstract}

(c) 2019 Elsevier Inc. All rights reserved.

\section{Introduction}

Chronic kidney disease (CKD) is a worldwide condition associated with high mortality and morbidity rates. ${ }^{1}$ It is well established that abnormalities in mineral metabolism are apparently early in the course of CKD and play a major role in accelerating metabolic abnormalities associated with CKD. ${ }^{1}$ One of the well-known consequences of CKD is predisposition to fragility fractures. Not only is the risk of fracture higher in the CKD population, but clinical outcomes are significantly worse. ${ }^{2}$ This is a particularly critical health burden in patients with diabetes, who are at a higher risk for bone fracture than a non-diabetic person. ${ }^{3,4}$

Contrary to what should be expected, and despite their elevated bone mineral density (BMD), patients with Type 2 diabetes mellitus (T2DM), are at an increased risk of fracture. In 2017, a systematic review and meta-analysis of published data on the association between diabetes

\footnotetext{
* Corresponding author.

E-mail address: al.ribeir@gmail.com (A.L. Ribeiro).
}

mellitus and fracture, showed the association between T2DM and increased risk of overall fracture. ${ }^{5}$

The primary function of bone is to maintain its structural integrity though a constant process of bone remodeling. Moreover, bone is also a key player in the regulation of mineral metabolism. More recently, bone was also recognized as an endocrine organ that releases two important hormones, fibroblast growth factor 23 (FGF-23) and undercarboxylated osteocalcin (Ocn). ${ }^{6,7}$ FGF-23 regulates phosphate and vitamin D metabolism and Ocn is an essential in energy metabolism, and sexual reproduction. ${ }^{8}$

Both FGF-23 and Ocn levels are increased in CKD, making these proteins promising potential bio-markers for bone remodeling in CKD. ${ }^{9,10}$ In addition, there are emerging data supporting that CKD patients with T2DM are at an increased risk for adynamic bone disease. ${ }^{11}$

In order to better prevent the occurrence of skeletal fracture it is important to better understand which could be the best biomarkers predisposing for bone fractures in populations at risk. In the present study, our main goal was to clarify the role of some bone related biochemical parameters and hormone levels in the predisposition for bone fractures in T2DM patients with CKD. 


\section{Material and methods}

\subsection{Subjects}

In an observational prospective study, we included 126 CKD patients with T2DM and 26 healthy individuals, recruited between 2010 and 2017 with a diagnosis of diabetic nephropathy (stages 2-3) in a stable clinical condition attending our outpatient clinic.

Institutional Ethics Committee approval (reference 207/2010) was obtained for this study.

The exclusion criteria were: Previous bone disease, age $<18$ years or $>75$ years, uncontrolled hypertension ( $\mathrm{BP} \geq 140 / 90 \mathrm{mmHg}$ ), albuminto-creatinine ratio $(A C R)>500$, estimated glomerular filtration rate (eGFR) $\leq 29$ or $>90 \mathrm{~mL} / \mathrm{min}$, type 1 diabetes, known neoplastic or infectious diseases, non-diabetic renal disease (patients without previous history of diabetes, with diagnosis of glomerulopathies associated with other pathologies like systemic diseases, IgA nephropathy, kidney disease of unknown ethology, chronic interstitial nephritis, vasculitis, component complement 3 pathologies or renal hereditary diseases. Patients with parathyroid hormone (PTH) $\geq 350 \mathrm{pg} / \mathrm{mL}$ were excluded to avoid bias from anti-hyperparathyroidism medication that can affect Klotho and FGF-23 levels. The same happened with patients with phosphorus $>5.5$ and the phosphorus-chelating agents that affect the Klotho-FGF-23 axis. Patients undergoing therapy with vitamin D and vitamin D receptor activators and phosphate binders, as well as anticoagulant therapies (varfine, enoxaparin, clopidogrel, and platelet antiaggregant) were also excluded.

\subsection{Follow-up}

Patients returned on a regular basis (every 3 months) for in-person visits on Nephrology consultation. No patient was "lost to follow-up".

\subsection{Blood measurements}

Fasting samples were drawn from all subjects, and plasma was frozen at $-80{ }^{\circ} \mathrm{C}$ in order to measure glomerular filtration rate (eGFR), phosphorus (P), calcium (Ca), osteocalcin (Ocn), hemoglobin ( $\mathrm{Hg})$, glycated hemoglobin (HbA1c), PTH, colesterol, albumine to creatinine ratio (ACR), insulin resistance degree (HOMA-IR), fibroblast growth factor-23 (FGF-23), 25(OH)D3 (vitamin D), oxidized low density lipoprotein (OxLDL), tumor necroses factor- alpha (TNF- $\alpha$ ), and soluble $\alpha$-Klotho (Klotho). FGF-23 levels were quantified using an enzymelinked immunosorbent assay, Human FGF-23 (C-Term) (Cat.\#60-6100 Immutopics Inc., San Clemente, CA, USA) and Human soluble $\alpha$ Klotho ELISA kit (Code No. 27998, IBL - Immuno-Biological Laboratories Co., Ltd., Gunma, Japan), according to the manufacturer's instructions. The degree of insulin resistance was estimated using the homeostasis model assessment (HOMA-IR) described by Matthews et al. ${ }^{12}$ We estimated the GFR according to the Chronic Kidney Disease Epidemiology Collaboration (CKD-EPI) Equation. ${ }^{13}$

\subsection{Outcomes}

The primary outcome of this study was occurrence of bone fracture.

\subsection{Statistical analyses}

Statistical analysis was performed with SPSS17.0 for Windows. Descriptive statistics, Chi-square and logistic regression were used. to compare CKD patients with or without the occurrence of bone fracture event to a control healthy population, we used ANOVA and a post-hoc analysis with Scheffe test. Continuous variables were presented as mean \pm standard error. A value of $<0.05$ was considered significant.

The hazard ratios (HR) were calculated using a backward stepwise likelihood ratio (LR) Cox regression for entry into renal replacement therapy (RRT). The logistic regression model was used to determine whether the variables were important predictive factors in the determination of occurrence of bone fracture event. Only the variables with a statistically significant relationship were introduced in a logistic regression model. The exponentials of the model parameters were the adjusted odds ratio (ORa) to other variables of the model. Prior to conducting the logistic regression and the Cox regression, subjects were categorized according to the 25th, 50th and 75th percentiles of FGF-23, Klotho, osteocalcin, phosphorus and oxLDL levels in the current study population were determined to exclude confounding factors that may influence the results. The subjects were categorized as follows: for FGF-23 group 1 (FGF-23<58), group 2 (FGF-23: 58-100) and group 3 (FGF-23 > 100); for Klotho group 1 (Klotho < 268), group 2 (Klotho: 268-440) and group 3 (Klotho > 440); for osteocalcin group 1 (Ocn $<16$ ), group 2 (Ocn: $16-24$ ) and group 3 (Ocn $>24$ ); for phosphorus group 1 (phosphorus $<3.7$ ), group 2 (phosphorus: $3.7-4.6$ ) and group 3 (phosphorus $>4.6$ ) and for oxLDL group 1 (oxLDL $<27$ ), group 2 (oxLDL: 27-36) and group 3 (oxLDL > 36). CKD stages were defined by the eGFR $\left(\mathrm{mL} / \mathrm{min} / 1.73 \mathrm{~m}^{2}\right.$ ), for Stage 2 (eGFR 60-89), for Stage 3a (eGFR 45-59), for Stage 3b (eGFR 30-44). The null hypothesis was rejected below the level of $5 \%$.

\section{Results}

One hundred and twenty-six (126) consenting patients with type 2 diabetes mellitus (T2DM) and stage 2-3 of chronic kidney disease (CKD) were included in the study after confirming they did not meet any of the exclusion criteria. A negative control of 26 healthy individuals was also incorporated in the study. The mean age was $58.10 \pm 6,66$ [range 41-68] years, and 41.8\% (64) were female.

Subjects were classified into three groups: CKD patients (and T2DM) with a fracture event, CKD patients (and T2DM) without a fracture event and a control population of healthy subjects. Table 1 displays patients' demographic and clinical parameters and a comparison between CKD patients (and T2DM) with a fracture event, CKD patients (and T2DM) without a fracture event and a control population of healthy subjects.

In Table 1 and Fig. 1, mean values of osteomineral parameters for CKD patients with T2DM, with and without the occurrence of bone fracture and for a control population of healthy individuals are listed.

CKD Patients with a fracture event displayed lower values for Osteocalcin $(p<0.001), \alpha$-Klotho $(p<0.001)$, and 25(OH)D3 $(p<0.001)$ when compared to both CKD patients without a fracture event and the control healthy subjects. Furthermore, CKD patients without a fracture event displayed lower $\alpha$-Klotho $(p<0.01)$ when compared to control

Table 1

Patients demographic and clinical characteristics at baseline. Chronic kidney disease (CKD) patients with type 2 diabetics (T2DM), with and without the occurrence of bone fracture and a control population of healthy subjects.

\begin{tabular}{lccc}
\hline Variable & $\begin{array}{c}\text { Fracture }(\mathrm{no}) \\
(n=100)\end{array}$ & $\begin{array}{l}\text { Fracture (yes) } \\
(n=26)\end{array}$ & $\begin{array}{l}\text { Control } \\
(n=27)\end{array}$ \\
\hline Age (years) & $56.99 \pm 6.69$ & $61.15 \pm 6.60$ & $59.30 \pm 5.69$ \\
Osteocalcin $(\mu \mathrm{g} / \mathrm{L})$ & $20.82 \pm 0.67$ & $8.88 \pm 1.30^{*}$ & $23.67 \pm 1.10$ \\
$\alpha-$ Klotho $(\mathrm{pg} / \mathrm{mL})$ & $379.08 \pm 15.07$ & $113.31 \pm 13.89^{*}$ & $490.67 \pm 8.76^{*}$ \\
FGF-23 $(\mathrm{RU} / \mathrm{mL})$ & $111.01 \pm 13.41$ & $304.63 \pm 27.02^{*}$ & $60.97 \pm 1.70$ \\
25(OH)D3 $(\mathrm{ng} / \mathrm{mL})$ & $22.73 \pm 0.71$ & $14.27 \pm 1.06^{*}$ & $25.87 \pm 0.39$ \\
OxLDL $(\mathrm{U} / \mathrm{L})$ & $36.81 \pm 1.82$ & $59.15 \pm 4.44^{*}$ & $29.65 \pm 0.81$ \\
TNF- $\alpha(\mathrm{pg} / \mathrm{mL})$ & $7.55 \pm 0.32$ & $11.32 \pm 0.90^{*}$ & $5.90 \pm 0.15$ \\
HOMA-IR & $1.55 \pm 0.16$ & $3.04 \pm 0.23^{*}$ & $0.55 \pm 0.01 *$ \\
Calcium $\times$ Phosphorus $(\mathrm{mg} / \mathrm{dL})$ & $35.95 \pm 0.91$ & $43.56 \pm 1.40^{*}$ & $28.47 \pm 1.38^{*}$ \\
ACR $(\mu \mathrm{g} / \mathrm{mg})$ & $161.22 \pm 1.10$ & $261.18 \pm 25.01^{*}$ & $114.70 \pm 10.36$ \\
PTH $(\mathrm{pg} / \mathrm{mL})$ & $100.35 \pm 7.09$ & $177.05 \pm 16.34 *$ & $73.30 \pm 1.85$ \\
Phosphorus $(\mathrm{mg} / \mathrm{dL})$ & $3.82 \pm 0.08$ & $4.52 \pm 0.15^{*}$ & $3.23 \pm 0.14^{*}$ \\
Calcium $(\mathrm{mg} / \mathrm{dL})$ & $9.52 \pm 0.07$ & $9.08 \pm 0.50$ & $8.97 \pm 0.13^{*}$ \\
eGFR $(\mathrm{mL} / \mathrm{min})$ & $51.95 \pm 1.66$ & $41.02 \pm 1.82^{*}$ & $103.53 \pm 1.37 *$ \\
\hline
\end{tabular}

Values are presented as mean \pm standard deviation. ${ }^{*} p<.001 ;{ }^{* *} p<.005$. All comparisons were made relative to CKD patients (and T2DM) without a fracture event. 


\section{Osteocalcin}

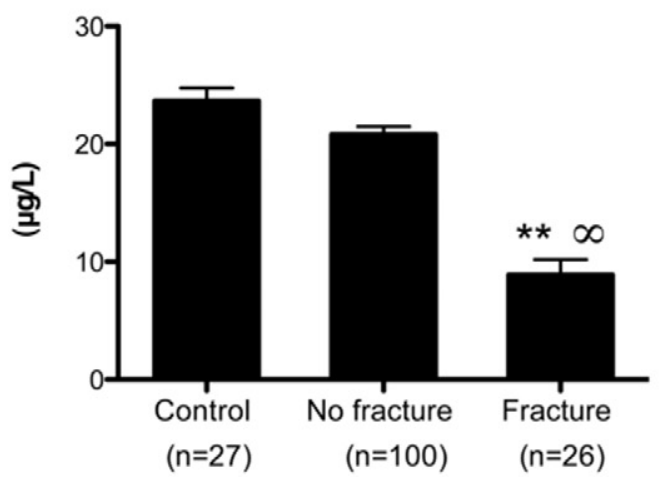

FGF-23

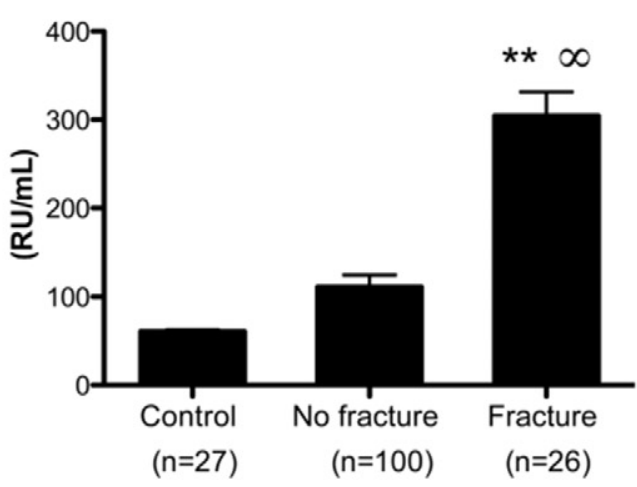

25(OH)D3

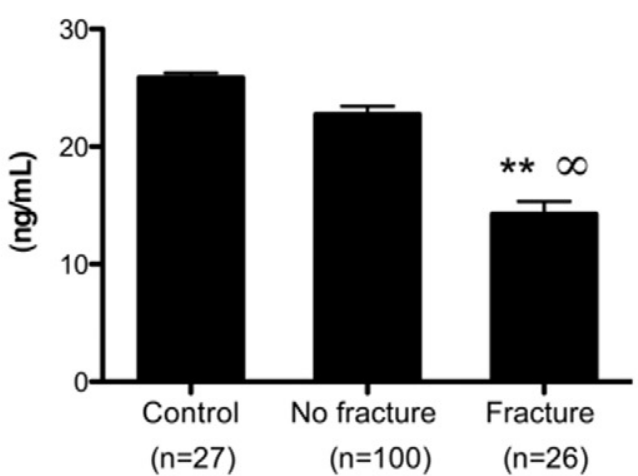

$\alpha-$ Klotho

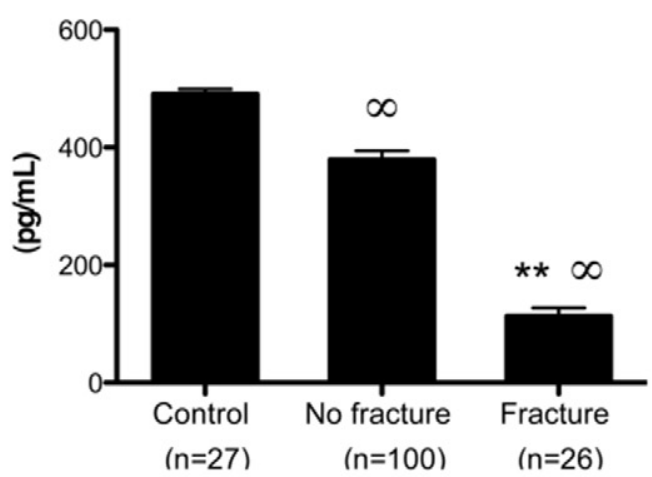

Phosphorus

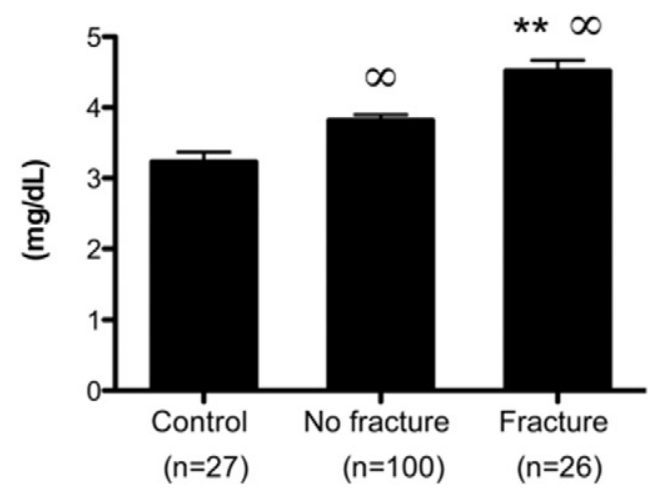

PTH

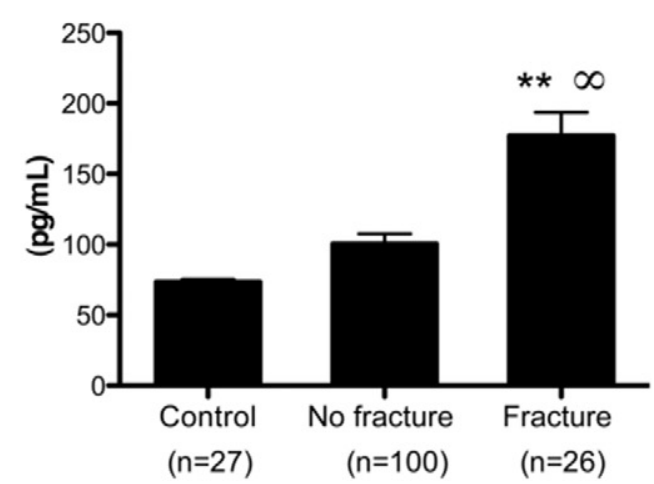

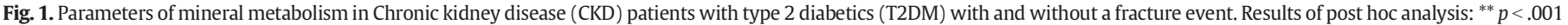
vs no fracture; $\propto p<.01$ vs control.

healthy subjects. On the other hand, the levels of FGF-23 ( $p<0.001)$, Phosphorus $(p<0.001)$ and PTH $(p<0.001)$ are increased in CKD patients with a fracture event. Moreover, the phosphorus levels of CKD patients without a fracture event are higher than those of the control population.

In Fig. 2, mean values of other parameter, such as inflammatory, oxidative stress, cardiovascular and kidney function markers are listed. TNF- $\alpha(p<0.001)$, OxLDL $(p<0.001)$, HOMA-IR $(p<0.001)$, calcium $\times$ phosphorus product $(p<0.001)$ and ACR $(p<0.001)$ are increased in CKD patients with a fracture event. Both HOMA-IR $(p<0.001)$ and calcium $\times$ phosphorus product $(p<0.001)$ are also increased in the CKD patients without a fracture event when compared to the healthy control subjects. eGFR levels were lower in all CKD patients but even lower in CKD patients with a fracture event $(p<0.01)$.

Fig. 3 shows the occurrence of a fracture event according to the stage of renal disease. The patients were classified into three stages of CKD, according to the eGFR $\left(\mathrm{mL} / \mathrm{min} / 1.73 \mathrm{~m}^{2}\right)$ : stage 2 (60-89), stage 3a (45-59) and stage 3b (30-44). The patients with a fracture event increase with inclining CKD stages $(\chi 2, p=006)$.

To evaluate the $\mathrm{OR}_{\mathrm{a}}$ of osteomineral parameters for CKD patients with T2DM, that are predictors of bone fracture event, a model of logistic regression analyses was used. All comparisons were made relative to the reference value of each osteomineral parameter. The logistic regression analysis (Table 2 ) revealed that age, osteocalcin, $\alpha$-Klotho and FGF23 independently influenced the occurrence of bone fracture $(p<0.05)$.

Variables such as gender, age, phosphorus, PTH, Osteocalcin, FGF-23, Klotho, 25(OH)D3, OxLDL and the occurrence of fracture were analyzed using a multivariate Cox regression to identify independent risk factors of entry into RRT. The occurrence of fracture and the levels of TNF- $\alpha$, klotho, 25( $\mathrm{OH}) \mathrm{D} 3$ and OxLDL were found to predict patient entry into RRT $(p<0.05)$ (Table 3$)$. 
TNF- $\alpha$

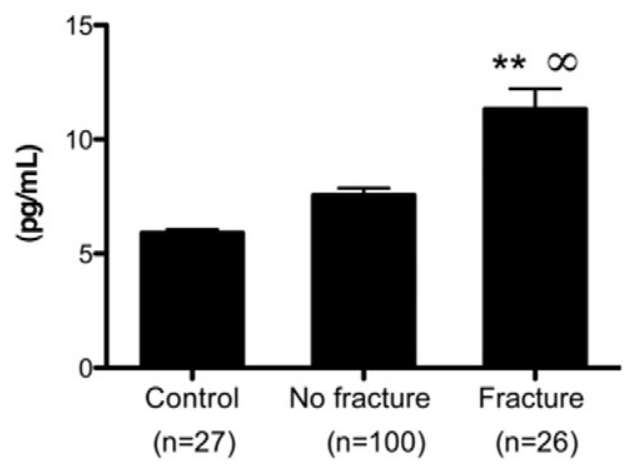

HOMA-IR

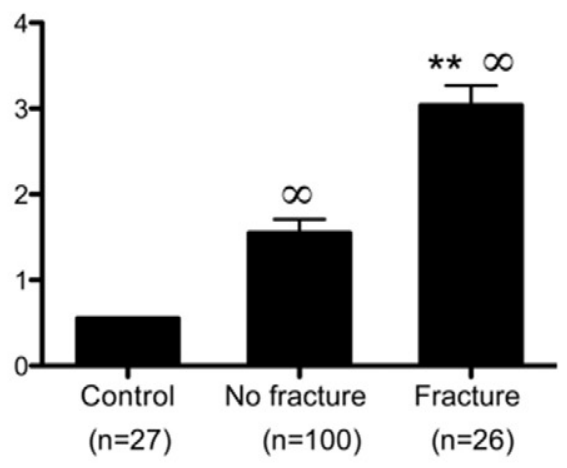

ACR

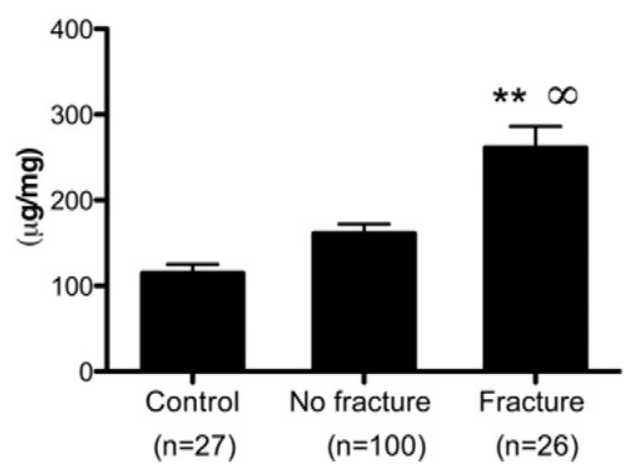

OXLDL

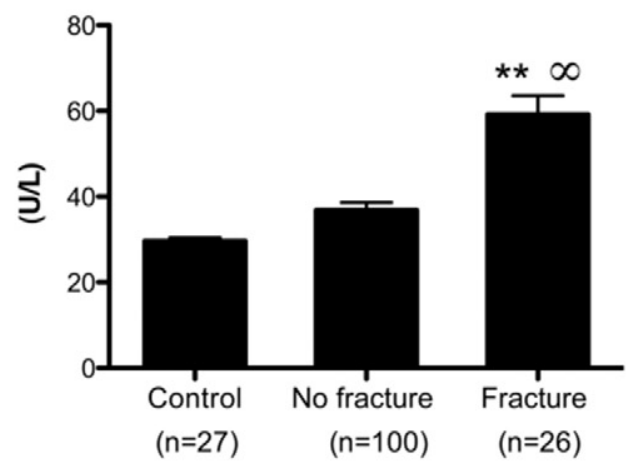

eGFR

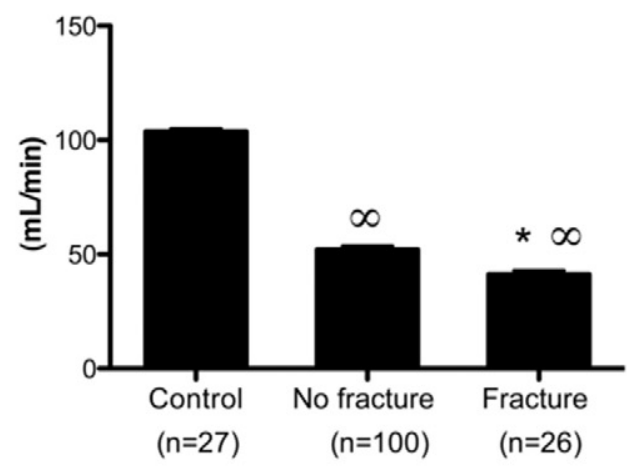

Calcium x Phosphorus

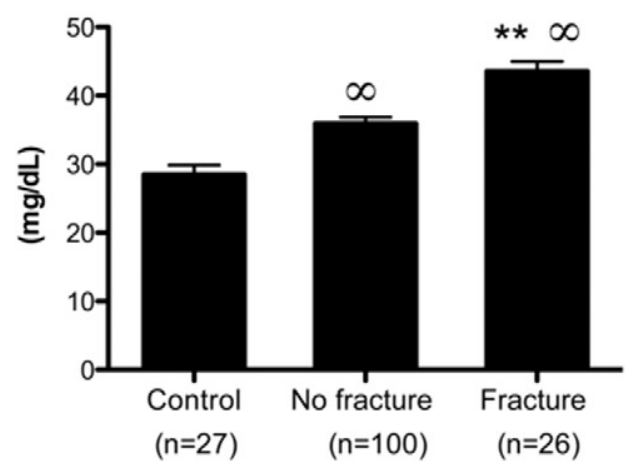

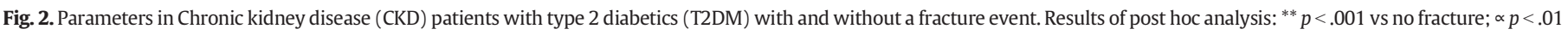
vs control.

\section{Discussion and conclusion}

As worldwide life expectancy continues to rise, the burden of fragility fractures is a persistently growing health problem. Bone fractures result in considerable morbidity, reduced lifetime and bigger health care costs; thus, it is urgent to find a good tool to identify patients with high fracture risk. The FRAX module identifies patients at risk of fracture considering the BMD, previous fracture, glucocorticoid use, and family history on the 10 -year risk for fracture, as independent risk factors for fracture. ${ }^{14}$ Identifying new biomarkers, such as hormones, for bone fragility would definitely improve this model as well as improve drug therapy to reduce fracture rates in high-risk populations. It is well established that diabetic CKD patients are at particularly high risk of bone fracture. ${ }^{15}$ Both low eGFR and higher albuminuria are considered significant risk factors for fracture. ${ }^{16}$ In this study, patients were classified into three stages of CKD, according to the eGFR ( $\left.\mathrm{mL} / \mathrm{min} / 1.73 \mathrm{~m}^{2}\right)$ : stage 2 (60-89), stage $3 \mathrm{a}(45-59)$ and stage $3 \mathrm{~b}(30-44)$. The number of patients with a fracture event was higher than expected within inclining CKD stages $(\chi 2, p=$ $0.06)$. Moreover, ACR are also increased in CKD patients with a fracture event $(p<0.001)$.

In this study, we found that in a population of T2DM CKD patients (stage 2 and 3), age, osteocalcin, $\alpha$-Klotho and FGF-23 levels independently influenced the occurrence of bone fracture. Interestingly, the association of higher FGF23 and lower Klotho levels with fracture occurrence is independent of eGFR.

Moreover, and using Cox analysis, the levels of TNF- $\alpha$, klotho, 25 $(\mathrm{OH}) \mathrm{D} 3$ and OxLDL and the occurrence of fracture were found to independently predict patient entry into RRT $(p<0.05)$.

These findings reinforce the idea that hormones and osteomineral parameters related to bone remodeling may be good candidates as biomarkers to predict the occurrence of fracture events.

Maintaining physiological phosphate balance is of crucial biological importance for bone health. Others and ourselves, have previously demonstrated that hyperphosphatemia is associated with greater 


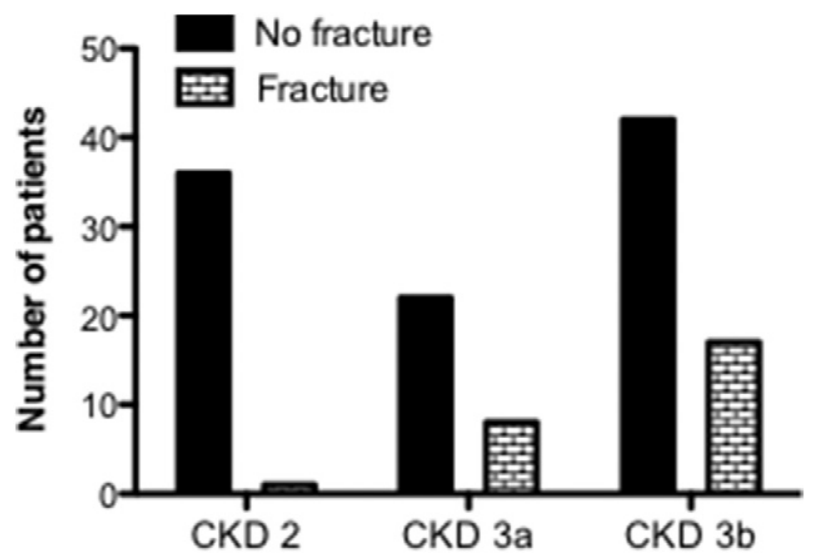

Fig. 3. The occurrence of a fracture event according to Chronic kidney disease (CKD) stage. (Pearson Chi-Square, $p=006$ ). The patients were classified into three stages of CKD, according to the eGFR ( $\left.\mathrm{mL} / \mathrm{min} / 1.73 \mathrm{~m}^{2}\right)$ : CKD 2 (60-89), CKD 3a (45-59) and CKD 3b (30-44).

cardiovascular mortality and morbidity even in patients in low to moderate stages of renal disease. ${ }^{17-19}$ In the present study we showed that the levels of Phosphorus are specially increased in CKD patients with a fracture event $(p<0.001)$.

FGF-23 is a key player in the homeostasis of serum phosphate levels. ${ }^{20}$ This hormone is secreted by osteocytes and osteoblasts in response to high phosphate levels, either caused by dietary phosphate intake or due to states of impaired renal excretion, such as chronic kidney disease. ${ }^{21,22}$ FGF-23 stimulates urinary phosphate excretion by suppressing type Ila sodium phosphate co-transporter in the renal proximal tubule. ${ }^{20}$ In the gut, FGF-23 reduces the efficiency of phosphate absorption by impairing production and accelerating degradation of the active form of vitamin D. ${ }^{23}$ Recent data suggest that FGF-23 can also directly inhibit the expression and secretion of PTH but, by promoting 1,25(OH)2D3 deficiency it may also contribute to the development of secondary hyperparathyroidism. ${ }^{24}$ Both PTH and vitamin D levels have been previously demonstrated to be informative for the definition of fracture risk in patients with CKD-mineral and bone disorders, being useful tools for the identification of CKD patients at high risk of fracture. ${ }^{25,26}$ In agreement with this, our results showed that, on the one hand, FGF23 and PTH levels were increased in CKD patients with a fracture event $(p<0.001)$, on the other hand, CKD patients with a fracture event displayed lower values for 25(OH)D3 $(p<0.001)$ when compared to both CKD patients without a fracture event and the control healthy subjects. Excessive levels of FGF-23 are associated with bone disorders such as tumor-induced osteomalacia. In these pathological conditions, FGF-23-dependent phosphaturia and calcitriol deficiency leads to severe bone loss, as well as to bone pain and fractures. ${ }^{27}$ Despite the numerous studies supporting that FGF-23 is a negative regulator of bone matrix mineralization both in vivo and in vitro ${ }^{28,29}$, the relationship between FGF-23 elevation (in early CKD) and fracture risk is still a matter of debate due to conflicting results. ${ }^{21,30-32}$ Some studies demonstrate an independent association between higher FGF-23 levels and greater fracture risk in elderly men ${ }^{31,32}$; whereas cross-sectional studies investigating the association of FGF- 23 with bone mineral density have also showed contradictory results, ${ }^{30,33,34}$ with the majority reporting no significant associations. ${ }^{21,30,34}$ In the present study we observed a relationship between elevated FGF-23 levels and fracture risk in the studied population of T2DM patients with low to moderate CKD. This is in agreement with previous studies reporting that FGF-23 was also found to be a predictor of CKD progression in diabetic ${ }^{35}$ and non-diabetic patients. ${ }^{36}$ Interestingly, numerous data on pleotropic effects of FGF-23 is also emerging, namely the association of elevated FGF-23 levels with multiple cardiovascular risk factors ${ }^{37-39}$ and mortality. ${ }^{40}$ All together, this makes FGF-23 a potential biomarker of multiple disarrangements leading to negative patient outcome.
Table 2

Predictive factors of fracture event.

\begin{tabular}{|c|c|c|c|}
\hline Variables & $\mathrm{OR}_{\mathrm{a}}$ & $95 \% \mathrm{CI}$ & $p$ values \\
\hline \multicolumn{4}{|l|}{ Gender } \\
\hline Male & Ref. & & \\
\hline Female & 1.893 & $0.255-2.035$ & 0.532 \\
\hline \multicolumn{4}{|l|}{ Age } \\
\hline$<65$ & Ref. & & \\
\hline$\geq 65$ & 2.206 & $1.07-4.50$ & 0.044 \\
\hline \multicolumn{4}{|l|}{ CKD stages } \\
\hline Stage $2(60-89)$ & Ref. & & \\
\hline Stage 3a (45-59) & 6.183 & 0.993-1.900 & 0.395 \\
\hline Stage 3b (30-44) & 9.537 & $0.146-3.192$ & 0.290 \\
\hline \multicolumn{4}{|l|}{ Phosphorus } \\
\hline$\leq 3.6$ & Ref. & & \\
\hline$>3.6-4.6$ & 0.332 & $0.613-8.783$ & 0.510 \\
\hline$>4.6$ & 1.058 & $0.846-4.586$ & 0.972 \\
\hline \multicolumn{4}{|l|}{ PTH } \\
\hline$<138$ & Ref. & & \\
\hline$\geq 138$ & 0.197 & $0.912-3.170$ & 0.252 \\
\hline \multicolumn{4}{|l|}{ HOMA-IR } \\
\hline$<2$ & Ref. & & \\
\hline$\geq 2$ & 1.783 & $0.221-8.169$ & 0.193 \\
\hline \multicolumn{4}{|l|}{ TNF- $\alpha$} \\
\hline$<8$ & Ref. & & \\
\hline$\geq 8$ & 2.027 & $0.735-3.507$ & 0.610 \\
\hline \multicolumn{4}{|l|}{ Osteocalcin } \\
\hline$<16$ & 1.016 & $1.001-1.389$ & 0.045 \\
\hline $16-24$ & 1.296 & $1.000-3.005$ & 0.007 \\
\hline$>24$ & Ref. & & \\
\hline \multicolumn{4}{|l|}{$\alpha$-Klotho } \\
\hline$<268$ & 1.226 & $1.001-1.678$ & 0.058 \\
\hline $268-440$ & 2.950 & $2.00-3.500$ & 0.037 \\
\hline$\geq 440$ & Ref. & & \\
\hline \multicolumn{4}{|l|}{ FGF-23 } \\
\hline$<58$ & Ref. & & \\
\hline $58-101$ & 1.788 & $1.001-2.366$ & 0.024 \\
\hline$>101$ & 3.853 & $2.020-7.428$ & 0.015 \\
\hline \multicolumn{4}{|l|}{$25(\mathrm{OH}) \mathrm{D} 3$} \\
\hline$\geq 21$ & Ref. & & \\
\hline$<21$ & 0.203 & $0.702-2.427$ & 0.201 \\
\hline \multicolumn{4}{|l|}{ OxLDL } \\
\hline$<27$ & Ref. & & \\
\hline $27-36$ & 1.032 & $0.351-3.021$ & 0.138 \\
\hline
\end{tabular}

Logistic regression model: $O R_{a}$ adjusted odds ratio, $95 \% \mathrm{CI}$ confidence interval for the odds ratio, Ref category versus the one is making comparisons.

In the majority of cases, FGF-23 signal transduction requires a binding to FGF receptor and $\alpha$-Klotho protein. ${ }^{41}$ Soluble Klotho is a multi-function protein present in the blood, urine, and cerebrospinal fluid and plays important roles in anti-aging, energy metabolism, inhibition of Wnt signaling, anti-oxidation, ion transport, control of PTH and $1,25(\mathrm{OH})_{2} \mathrm{VD}_{3}$ production, inhibition of insulin and antagonism of renin-angiotensin-aldosterone system. $\alpha$-Klotho is stimulated by $1,25(\mathrm{OH})_{2} \mathrm{VD}_{3}$ and inhibited by FGF-23 thereby creating an endocrine loop, as circulating Klotho can activate FGF-23-FGFR signaling. ${ }^{42}$ In the majority of clinical studies CKD has been described has a state of FGF-23 resistance due to endocrine and renal Klotho deficiency. ${ }^{43}$

In this study, lower levels of Klotho seem to be an independent predictive factor for bone fracture, in T2DM patients with CKD. Interestingly, data suggesting that TNF- $\alpha$ is able to downregulate Klotho expression, ${ }^{44}$ is also in line with our results, showing increased levels of the inflammatory cytokine TNF- $\alpha$ and decreased levels of Klotho in type 2 diabetic patients with CKD with a fracture event. Thus, it is not unreasonable to hypothesize that elevated Klotho levels may serve as an early biomarker 
Table 3

Predictive factors for entry into renal function replacement technique.

\begin{tabular}{|c|c|c|c|}
\hline Variables & Adjusted HR & $95 \% \mathrm{CI}$ & $p$ values \\
\hline \multicolumn{4}{|l|}{ Gender } \\
\hline Female & Ref. & & \\
\hline Male & 3.702 & $0.670-2.462$ & 0.133 \\
\hline \multicolumn{4}{|l|}{ Age } \\
\hline$<65$ & Ref. & & \\
\hline$\geq 65$ & 0.385 & $0.048-3.067$ & 0.385 \\
\hline \multicolumn{4}{|l|}{ ACR } \\
\hline$<95$ & Ref. & & \\
\hline $95-235$ & 2.133 & $0.126-36.041$ & 0.600 \\
\hline$>235$ & 2.573 & $1.935-6.133$ & 0.050 \\
\hline \multicolumn{4}{|c|}{ Phosphorus } \\
\hline$\leq 3.6$ & Ref. & & \\
\hline$>3.6-4.6$ & 0.590 & $0.031-1.192$ & 0.725 \\
\hline$>4.6$ & 0.333 & $0.012-9.507$ & 0.520 \\
\hline \multicolumn{4}{|l|}{ PTH } \\
\hline$<138$ & Ref. & & \\
\hline$\geq 138$ & 3.669 & $0.270-4.797$ & 0.329 \\
\hline \multicolumn{4}{|l|}{ Fracture } \\
\hline No & Ref. & & \\
\hline Yes & 8.036 & $1.267-9.988$ & 0.027 \\
\hline \multicolumn{4}{|l|}{ TNF- $\alpha$} \\
\hline$<8$ & Ref. & & \\
\hline$\geq 8$ & 1.076 & $1.001-4.755$ & 0.014 \\
\hline \multicolumn{4}{|c|}{ Osteocalcin } \\
\hline$<16$ & 1.442 & $3.023-1.080$ & 0.889 \\
\hline $16-24$ & 3.684 & $0.421-9.849$ & 0.907 \\
\hline$>24$ & Ref. & & \\
\hline \multicolumn{4}{|l|}{$\alpha$-Klotho } \\
\hline$<268$ & 6.762 & $0.872-8.718$ & 0.060 \\
\hline $268-440$ & 1.159 & $1.010-2.523$ & 0.042 \\
\hline$\geq 440$ & Ref. & & \\
\hline \multicolumn{4}{|l|}{ FGF-23 } \\
\hline$<58$ & Ref. & & \\
\hline $58-101$ & 3.910 & $0.725-6.839$ & 0.081 \\
\hline$>101$ & 0.485 & $0.203-1.847$ & 0.776 \\
\hline \multicolumn{4}{|l|}{$25(\mathrm{OH}) \mathrm{D} 3$} \\
\hline$\geq 21$ & Ref. & & \\
\hline$<21$ & 2.184 & $1.824-3.125$ & 0.009 \\
\hline \multicolumn{4}{|l|}{ OxLDL } \\
\hline$<27$ & Ref. & & \\
\hline $27-36$ & 1.183 & $1.081-2.758$ & 0.040 \\
\hline$>36$ & 2.543 & $1.406-2.368$ & 0.026 \\
\hline
\end{tabular}

Multivariate Cox regression: HR hazard ratio. 95\% CI confidence interval for the HR. Ref category versus the one is making comparisons.

and a pathogenic contributor to chronic progression and complications in chronic kidney disease, such as bone fragility.

However, it is still controversial whether osteocalcin is a good marker of bone formation ${ }^{4546}$ and the fact that initially $\mathrm{OC}$ was believed to be only necessary to maintain the normal calcification and inhibit mineralization, more recently a much wide role of OC has been suggested in overall body metabolism, reproduction, cognition as well as regulating insulin production and secretion. ${ }^{47}$ Our results show that, not only do low levels of $\mathrm{OC}$ independently influenced the risk for bone fracture in T2DM CKD patients, but patients with a bone fracture event also presented higher HOMA-IR values when compared to the ones without a fracture event, at least considering the population in this study. This is in line with previous results from Xuefei et al., showing that OC might improve glucose metabolism through increasing insulin secretion and improving insulin resistance in females with T2DM. ${ }^{48}$

Despite some limitations, namely the small size of the sample and the limited statistical power of these analyses, this study offers an added value by generating hypotheses. Nonetheless, further studies are required in order to confirm the observed associations.

In conclusion, the present study strongly suggests that a deregulation in mineral metabolism, reflected by low levels of Osteocalcin and Klotho and high levels of FGF-23, could be associated with an increased risk of bone fracture in T2DM patients with a diagnosis of mild to moderate CKD.

We believe the assessment of fracture risk can be better predicted by using a combination of biochemical markers of bone turnover - which are dynamic markers, and the BMD measurement - which provides a static picture of the skeleton, than by assessing either alone.

\section{Funding}

This research did not receive any specific grant from funding agencies in the public, commercial, or not-for-profit sectors.

\section{Declaration of competing interest}

The results presented in this paper have not been published previously in whole or part, except in abstract form.

\section{References}

1. Hill NR, Fatoba ST, Oke JL, et al. Global prevalence of chronic kidney disease - a systematic review and meta-analysis. PLoS One 2016;11, e0158765. https://doi.org/10. 1371/journal.pone.0158765.

2. Kazama JJ. Chronic kidney disease and fragility fracture. Clin Exp Nephrol 2017;21: 46-52. https://doi.org/10.1007/s10157-016-1368-3.

3. Sellmeyer DE, Civitelli R, Hofbauer LC, Khosla S, Lecka-Czernik B, Schwartz AV. Skeletal metabolism, fracture risk, and fracture outcomes in type 1 and type 2 diabetes. Diabetes 2016;65:1757-66. https://doi.org/10.2337/db16-0063.

4. Sanches CP, Vianna AGD. Barreto F de C. the impact of type 2 diabetes on bone metabolism. Diabetol Metab Syndr 2017;9. https://doi.org/10.1186/s13098-017-0278-1.

5. Moayeri A, Mohamadpour M, Mousavi SF, Shirzadpour E, Mohamadpour S, Amraei M. Fracture risk in patients with type 2 diabetes mellitus and possible risk factors: a systematic review and meta-analysis. Ther Clin Risk Manag 2017;13:455-68. https://doi.org/10.2147/TCRM.S131945.

6. Ferron M, Wei J, Yoshizawa T, et al. Insulin signaling in osteoblasts integrates bone remodeling and energy metabolism. Cell 2010;142:296-308. https://doi.org/10. 1016/j.cell.2010.06.003.

7. Pi M, Wu Y, Quarles LD. GPRC6A mediates responses to osteocalcin in $\beta$-cells in vitro and pancreas in vivo. J Bone Miner Res 2011;26:1680-3. https://doi.org/10.1002/jbmr.390.

8. Quarles LD. The bone and beyond: "Dem bones" are made for more than walking. Nat Med 2011;17:428-30. https://doi.org/10.1038/nm0411-428.

9. Stubbs J, Liu S, Quarles LD. Role of fibroblast growth factor 23 in phosphate homeostasis and pathogenesis of disordered mineral metabolism in chronic kidney disease. Semin Dial 2007;20:302-8. https://doi.org/10.1111/j.1525-139X.2007.00308.x.

10. Bacchetta J, Boutroy S, Guebre-Egziabher F, et al. The relationship between adipokines, osteocalcin and bone quality in chronic kidney disease. Nephrol Dial Transplant 2009;24:3120-5. https://doi.org/10.1093/ndt/gfp262.

11. Ray S, Beatrice AM, Ghosh A, et al. Profile of chronic kidney disease related-mineral bone disorders in newly diagnosed advanced predialysis diabetic kidney disease patients: a hospital based cross-sectional study. Diabetes Metab Syndr Clin Res Rev 2017;11:S931-7. https://doi.org/10.1016/j.dsx.2017.07.019.

12. Wallace TM, Levy JC, Matthews DR. Use and abuse of HOMA modeling. Diabetes Care 2004;27:1487-95. http://www.ncbi.nlm.nih.gov/pubmed/15161807 [Accessed January 4, 2018].

13. Levey AS, Stevens LA, Schmid CH, et al. A new equation to estimate glomerular filtration rate. Ann Intern Med 2009;150:604-12. http://www.ncbi.nlm.nih.gov/pubmed/ 19414839 [Accessed January 4, 2018].

14. Fracture Risk Assessment Tool (FRAX). http://www.univadis.pt/frax/191/FractureRisk-Assessment-Tool-FRAX?gclid=EAIaIQobChMIw439haG-2AIViT4bCh0n5QjEAAYASAAEgICAvD_BwE\#? Accessed January 4, 2018.

15. Moseley KF. Type 2 diabetes and bone fractures. Curr Opin Endocrinol Diabetes Obes 2012;19:128-35. https://doi.org/10.1097/MED.0b013e328350a6e1.

16. Daya NR, Voskertchian A, Schneider ALC, et al. Kidney function and fracture risk: the atherosclerosis risk in communities (ARIC) study. Am J Kidney Dis 2016;67:218-26. https://doi.org/10.1053/j.ajkd.2015.06.020.

17. Silva AP, Fragoso A, Pinho A, et al. Phosphorus as an early marker of morbidity and mortality in type 2 chronic kidney disease diabetic patients. J Diabetes Complications 2013;27:328-32. https://doi.org/10.1016/j.jdiacomp.2013.02.007.

18. Block GA, Hulbert-Shearon TE, Levin NW, Port FK. Association of serum phosphorus and calcium $\times$ phosphate product with mortality risk in chronic hemodialysis patients: a national study. Am J Kidney Dis 1998;31:607-17. http://www.ncbi.nlm.nih. gov/pubmed/9531176 [Accessed January 4, 2018].

19. Pinkau T, Hilgers KF, Veelken R, Mann JFE. How does minor renal dysfunction influence cardiovascular risk and the management of cardiovascular disease? J Am Soc Nephrol 2004;15:517-23. https://doi.org/10.1097/01.ASN.0000107565.17553.71. 
20. Wolf M. Forging forward with 10 burning questions on FGF23 in kidney disease. J Am Soc Nephrol 2010;21:1427-35. https://doi.org/10.1681/ASN.2009121293.

21. Isakova T, Cai X, Lee J, et al. Associations of FGF23 with change in bone mineral density and fracture risk in older individuals. J Bone Miner Res 2016;31:742-8. https://doi.org/10.1002/jbmr.2750.

22. Isakova T, Wahl P, Vargas GS, et al. Fibroblast growth factor 23 is elevated before parathyroid hormone and phosphate in chronic kidney disease. Kidney Int 2011;79:1370-8. https://doi.org/10.1038/ki.2011.47.

23. Shimada T, Kakitani M, Yamazaki Y, et al. Targeted ablation of Fgf23 demonstrates an essential physiological role of FGF23 in phosphate and vitamin D metabolism. J Clin Invest 2004;113:561-8. https://doi.org/10.1172/JCI19081.

24. Bernheim J, Benchetrit S. The potential roles of FGF23 and Klotho in the prognosis of renal and cardiovascular diseases. Nephrol Dial Transplant 2011;26:2433-8 https://doi.org/10.1093/ndt/gfr208.

25. Torres PAU, Cohen-Solal M. Evaluation of fracture risk in chronic kidney disease. J Nephrol 2017;30:653-61. https://doi.org/10.1007/s40620-017-0398-6.

26. Fusaro M, Aghi A, Mereu MC, Giusti A. [Fragility fracture in the Chronic Kidney Disease (CKD)]. G Ital Nefrol. 2017;34(Nov-Dec). http://www.ncbi.nlm.nih.gov/ pubmed/29207223. Accessed January 4, 2018.

27. Zimering MB, Caldarella FA, White KE, Econs MJ. Persistent tumor-induced osteomalacia confirmed by elevated postoperative levels of serum fiberoblast growth factor23 and 5-year follow-up of bone density changes. Endocr Pract 2005;11:108-14. https://doi.org/10.4158/EP.11.2.108.

28. Wang H, Yoshiko Y, Yamamoto R, et al. Overexpression of fibroblast growth factor 23 suppresses osteoblast differentiation and matrix mineralization in vitro. J Bone Miner Res 2008;23:939-48. https://doi.org/10.1359/jbmr.080220.

29. Sitara D, Kim S, Razzaque MS, et al. Genetic evidence of serum phosphateindependent functions of FGF-23 on bone. Cox GA, ed PLoS Genet 2008;4, e1000154. https://doi.org/10.1371/journal.pgen.1000154.

30. Jovanovich $\mathrm{A}$, Bùzková $\mathrm{P}$, Chonchol $\mathrm{M}$, et al. Fibroblast growth factor 23 , bone mineral density, and risk of hip fracture among older adults: the cardiovascular health study. J Clin Endocrinol Metab 2013;98:3323-31. https://doi.org/10.1210/jc.2013-1152.

31. Lane NE, Parimi N, Corr M, et al. Association of serum fibroblast growth factor 23 (FGF23) and incident fractures in older men: the osteoporotic fractures in men (MrOS) study. J Bone Miner Res 2013;28:2325-32. https://doi.org/10.1002/jbmr.1985.

32. Mirza MAI, Karlsson MK, Mellström D, et al. Serum fibroblast growth factor-23 (FGF-23) and fracture risk in elderly men. J Bone Miner Res 2011;26:857-64. https://doi.org/10. 1002/jbmr.263.

33. Manghat P, Fraser WD, Wierzbicki AS, Fogelman I, Goldsmith DJ, Hampson G. Fibroblast growth factor-23 is associated with C-reactive protein, serum phosphate and bone mineral density in chronic kidney disease. Osteoporos Int 2010;21:1853-61. https://doi.org/10.1007/s00198-009-1142-4.
34. Desjardins L, Liabeuf S, Renard C, et al. FGF23 is independently associated with vascular calcification but not bone mineral density in patients at various CKD stages. Osteoporos Int 2012;23:2017-25. https://doi.org/10.1007/s00198-011-1838-0.

35. Titan SM, Zatz R, Graciolli FG, et al. FGF-23 as a predictor of renal outcome in diabetic nephropathy. Clin J Am Soc Nephrol 2011;6:241-7. https://doi.org/10.2215/CJN.04250510.

36. Fliser D, Kollerits B, Neyer U, et al. Fibroblast growth factor 23 (FGF23) predicts progression of chronic kidney disease: the Mild to Moderate Kidney Disease (MMKD) study. J Am Soc Nephrol 2007;18:2600-8. https://doi.org/10.1681/ASN.2006080936.

37. Silva AP, Mendes F, Fragoso A, et al. Altered serum levels of FGF-23 and magnesium are independent risk factors for an increased albumin-to-creatinine ratio in type 2 diabetics with chronic kidney disease. J Diabetes Complications 2016;30:275-80. https://doi.org/10.1016/j.jdiacomp.2015.11.006.

38. Mirza MAI, Larsson A, Lind L, Larsson TE. Circulating fibroblast growth factor-23 is associated with vascular dysfunction in the community. Atherosclerosis 2009;205: 385-90. https://doi.org/10.1016/j.atherosclerosis.2009.01.001.

39. Yilmaz MI, Sonmez A, Saglam M, et al. FGF-23 and vascular dysfunction in patients with stage 3 and 4 chronic kidney disease. Kidney Int 2010;78:679-85. https://doi.org/10. 1038/ki.2010.194.

40. Gutiérrez OM, Mannstadt M, Isakova T, et al. Fibroblast growth factor 23 and mortality among patients undergoing hemodialysis. N Engl J Med 2008;359: 584-92. https://doi.org/10.1056/NEJMoa0706130.

41. Urakawa I, Yamazaki Y, Shimada T, et al. Klotho converts canonical FGF receptor into a specific receptor for FGF23. Nature 2006;444:770-4. https://doi.org/10.1038/ nature05315.

42. Silva AP, Mendes F, Pereira L, et al. Klotho levels: association with insulin resistance and albumin-to-creatinine ratio in type 2 diabetic patients. Int Urol Nephrol 2017;49:1809-14. https://doi.org/10.1007/s11255-017-1646-3.

43. Hu MC, Kuro-o M, Moe OW. Klotho and Chronic kidney disease. Contributions to Nephrology. Vol 180; 2013. p. 47-63. https://doi.org/10.1159/000346778.

44. Moreno JA, Izquierdo MC, Sanchez-Niño MD, et al. The inflammatory cytokines TWEAK and TNF $\alpha$ reduce renal klotho expression through NFKB. J Am Soc Nephrol 2011;22:1315-25. https://doi.org/10.1681/ASN.2010101073.

45. Ducy P, Desbois C, Boyce B, et al. Increased bone formation in osteocalcin-deficient mice. Nature 1996;382:448-52. https://doi.org/10.1038/382448a0.

46. Ducy P. The role of osteocalcin in the endocrine cross-talk between bone remodelling and energy metabolism. Diabetologia 2011;54:1291-7. https://doi.org/10.1007/ s00125-011-2155-z

47. Lee NK, Sowa H, Hinoi E, et al. Endocrine regulation of energy metabolism by the skeleton. Cell 2007;130:456-69. https://doi.org/10.1016/j.cell.2007.05.047.

48. Qu S, Xu B, Su J, et al. Differential pattern for regulating insulin secretion, insulin resistance, and lipid metabolism by osteocalcin in male and female T2DM patients. Med Sci Monit 2014;20:711-9. https://doi.org/10.12659/MSM.890130. 